\title{
Random Vibration Model in Linear and Non Linear Structure, Application in Engineering Structure
}

\author{
Anwar Dolu ${ }^{1^{*}}$, Amrinsyah Nasution ${ }^{2}$ \\ ${ }^{1}$ Lecturer, Faculty of Civil Engineering, Tadulako University, Central Sulawesi \\ ${ }^{2}$ Professor of Civil Engineering, Faculty of Civil Engineering \& Enviromental \\ Bandung Institute of Technology (ITB)
}

Received: 23 June 2015, Revised: 6 Aughust 2015, Accepted: 21 December 2015

\begin{abstract}
Response of linear or complex nonlinear structures takes form in a characteristic functions and in the deterministic or stochastic external loads. Non linear model with non linear structure stiffness is a type of Duffing equation. Stochastic external loads system is referred to a random signal white noise with a constant power spectral density (So), while non linear system identification of deterministic system's is based on time history, phase plane and Poincare map. Methods of Galerkin and Runge-Kutta are used to solve the partial non linear governing diferential equations. Mean value, Standard deviation and Probability Density Function (PDF) is stated as statistical responses due to stochastic response of random variables. The analysis of random vibration in the solution of non linear stochastic differential equation is solved numerically by Monte Carlo simulation and analitically by Fokker-Planck-Kolmogorov (FPK) equation.
\end{abstract}

Keywords: Nonlinier Random Vibration, Displacement Response, Standard Deviation, PDF, FPK, Monte Carlo

\section{INTRODUCTION}

Winds, waves and seismic forces are commonly a stochastic loads system on the engineering structures. Therefore, a random vibration analysis is essential to understand behaviour of structures. One may find the fundamental theory of random vibration theory in [1 - 9]. In general, solution of random vibration is by numerical approach to nonlinear response system calculation of standard deviation and the probability density function (PDF). The analytical solution limited to a special case. Solution method in general to the vibration system of linear and nonlinear random vibration by $[2,4,5,7-9], 1)$. FokkerPlanck-Kolmogorov (FPK) method, 2). Statistic Linearization method, 3). Gaussian closure and 4). Monte Carlo simulation.

This paper discusses simply supported beam subjected to a concentration vertical load $\mathrm{P}(\mathrm{x}, \mathrm{t})$ of stochastic type and horizontal load $\mathrm{Nx}$ of

\footnotetext{
Corresponding author.

E-mail address: anwardolu@yahoo.com
}

deterministic type. Nonlinear partial differential equations of beam takes form of equation (1), of which by the Galerkin method is reduced to nonlinear ordinary differential equation $(5,7)$. Equation (7) is solved by Runge - Kutta method. Displacements due to deterministic and stochastic loading systems are the structure response.

\section{VIBRATION NON- LINEAR DIFFERENTIAL EQUATION}

Beam vibration non-linear differential equation undergoes large deflection with nonlinear geometry due to stretching and axial forces is expressed in equation (1)

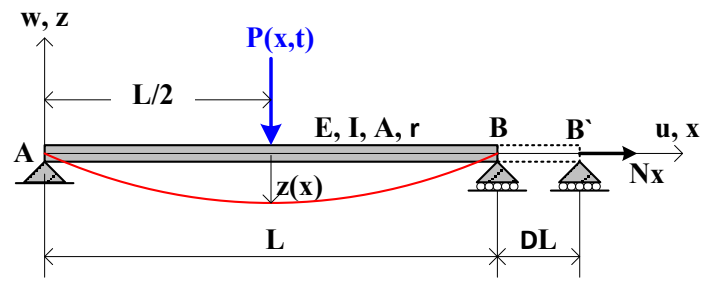

Fig. 1. Simply Supported Beam 
The partial differential equation takes form of $[10$, $11,13]$ :

$$
\begin{aligned}
& \rho \mathrm{A} \frac{\partial^{2} \mathrm{w}}{\partial \mathrm{t}^{2}}+\mathrm{c} \frac{\partial \mathrm{w}}{\partial \mathrm{t}}+\mathrm{EI} \frac{\partial^{4} \mathrm{w}}{\partial \mathrm{x}^{4}} \\
& +\left[\mathrm{N}_{\mathrm{x}}-\frac{\mathrm{EA}}{2 \mathrm{~L}} \int_{0}^{\mathrm{L}}\left(\frac{\partial \mathrm{w}}{\partial \mathrm{x}}\right)^{2} \mathrm{dx}\right] \frac{\partial^{2} \mathrm{w}}{\partial \mathrm{x}^{2}}=\mathrm{P}(\mathrm{x}, \mathrm{t})
\end{aligned}
$$

$\rho \mathrm{A}=$ beam mass, $\mathrm{c}=$ damping, $\mathrm{EI}=$ bending stiffness, $\mathrm{N}=$ axial force, $\mathrm{P}(\mathrm{x}, \mathrm{t})=$ vertical load. Equation (1) describes relationship dynamic equilibrium between the internal forces and the external loads of the structure system. Terms 1, 2 and 3 are linear components corresponding to EulerBernoulli's theory, and the terms 3 to 4 are nonlinear components due to stretching and axial force. Solution of equation (1) for the displacement $\mathrm{w}(\mathrm{x}, \mathrm{t})$ assuming :

$$
\mathrm{w}(\mathrm{x}, \mathrm{t})=\sum_{\mathrm{n}=1}^{\infty} \Phi_{\mathrm{n}}(\mathrm{x}) \mathrm{q}_{\mathrm{n}}(\mathrm{t})
$$

To $\Phi_{\mathrm{n}}$ is function of normal modes, $\mathrm{q}_{\mathrm{n}}(\mathrm{t})$ is modal coordinate. By the use of Galerkin procedure [1013]

$$
\begin{aligned}
& \int_{\Omega} \mathrm{R} \psi_{\mathrm{j}} \mathrm{d} \Omega=0 ; \psi_{\mathrm{j}}=\Phi_{\mathrm{n}}(\mathrm{x}) \\
& \int_{0}^{\mathrm{L}} \mathrm{R}(\mathrm{x}) \Phi_{\mathrm{n}}(\mathrm{x}) \mathrm{dx}=0 \quad \mathrm{n}=1,2, \ldots
\end{aligned}
$$

Boundary conditions for hinge and roll supports:

$$
\Phi(\mathrm{x}=0, \mathrm{~L})=\Phi^{\prime \prime}(\mathrm{x}=0, \mathrm{~L})=0
$$

One may find

$$
M \&(t)+C \&(t)-K_{1 N} q(t)+K_{3} q^{3}(t)=F
$$

of which

$$
\begin{gathered}
\mathrm{M}=\frac{\rho \mathrm{AL}}{2} ; \mathrm{C}=\frac{\mathrm{cL}}{2} ; \mathrm{K}_{1}=\frac{\mathrm{EI} \pi^{4}}{2 \mathrm{~L}^{3}} \\
\mathrm{~K}_{1 \mathrm{~N}}=\left[\left(\frac{\mathrm{NL}^{2}}{\mathrm{EI} \pi^{2}}\right)-1\right] \mathrm{K}_{1} ; \mathrm{K}_{3}=\frac{\mathrm{EA \pi ^{4 }}}{8 \mathrm{~L}^{3}}
\end{gathered}
$$

Simplify equation $(5,6)$ in the form of nondimensional

$$
\begin{aligned}
& \&(\mathrm{t})+2 \zeta \omega_{\mathrm{n}} \&(\mathrm{t})-\alpha \mathrm{q}(\mathrm{t})+\beta \mathrm{q}^{3}(\mathrm{t})=\overline{\mathrm{F}} \\
& \omega_{\mathrm{n}}^{2}=\frac{\mathrm{K}_{1}}{\mathrm{M}}(\text { natural frequency }) \\
& \alpha=\omega_{\mathrm{n}}^{2}\left(\frac{\mathrm{N}}{\mathrm{N}_{\mathrm{cr}}}-1\right) ; \beta=\frac{\mathrm{K}_{3}}{\mathrm{M}} ; \overline{\mathrm{F}}=\frac{\mathrm{F}}{\mathrm{M}} \\
& \mathrm{N}_{\mathrm{cr}}=\frac{\mathrm{EI} \pi^{2}}{\mathrm{~L}^{2}}(\text { Euler load })
\end{aligned}
$$

Equations $(7,8)$ are solved by Runge - Kutta method.

\section{WHITE NOISE PROCESSES}

The stochastic load W (t) is modeled as in the form of white noise. Stationary Gaussian white noise process is defined as a process that has a uniform spectral density function of the intensity $\mathrm{S}_{0}$ through the entire frequency area

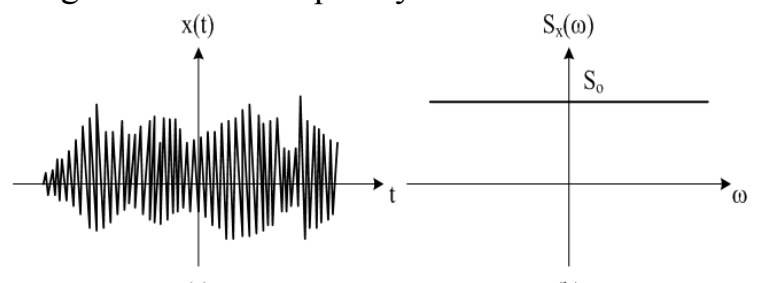

(a)

(b)

Fig. 2. White Noise process, (a). Time History, (b). Power Spectral Density ${ }^{[3,8]}$

\section{FOKKER-PLANCK-KOLMOGOROV (FPK) EQUATION}

Equation of Fokker - Planck - Kolmogorov FPK depicts the evolution of time and space of a probability density function (PDF) a stochastic dynamics of the system or be used to predict the properties of the response system [7-9,14-15]. The general form of Equation of Fokker - Planck Kolmogorov [8]

$$
\begin{aligned}
& \frac{\partial \mathrm{P}}{\partial \mathrm{t}}+\sum_{\mathrm{i}=1}^{\mathrm{n}} \frac{\partial}{\partial \mathrm{y}_{\mathrm{i}}}\left(\mu_{\mathrm{i}} \mathrm{P}\right) \\
& -\frac{1}{2} \sum_{\mathrm{i}=1}^{\mathrm{n}} \sum_{\mathrm{k}=1}^{\mathrm{n}} \frac{\partial^{2}}{\partial \mathrm{y}_{\mathrm{i}} \partial \mathrm{y}_{\mathrm{k}}}\left(\sum_{\mathrm{i}=1}^{\mathrm{n}} \sigma_{\mathrm{il}} \sigma_{\mathrm{kl}} \mathrm{P}\right)=0
\end{aligned}
$$

For $\mathrm{P}=$ probability, $\mu_{\mathrm{i}}=\mathrm{drift}, \sigma=$ diffusion. With external load of stochastic type white noise, the zero-mean and the spectral density So, then by equation (7)

$$
\Phi(t)+2 \zeta \omega_{n} \&(t)-\alpha q(t)+\beta q^{3}(t)=W(t)
$$

Based on the equation $(9,10)$, the form of the equation of the Fokker-Planck-Kolmogorov

$$
\begin{aligned}
& \frac{\partial P}{\partial t}=-\frac{\partial}{\partial q_{1}}\left(q_{2} P\right) \\
& -\frac{\partial P}{\partial q_{2}}\left[\left(\alpha q_{1}-\beta q_{1}^{2}-2 \zeta \omega_{n} q_{2}\right) P\right]+\frac{\pi S o}{M^{2}} \frac{\partial^{2} P}{\partial q_{2}^{2}}
\end{aligned}
$$

For $\mathrm{q}_{1}=$ modal displacement, $\mathrm{q}_{2}=$ modal velocity (\&). Completion equation (11) for the probability density function (PDF) modal displacement $\left(\mathrm{q}_{1}\right)$ at steady state conditions.

$$
P_{q}=C e^{\left[-\frac{2 \zeta \omega_{n}}{\pi S o}\left(\frac{1}{2} \alpha q^{2}+\frac{1}{4} \beta q^{4}\right)\right]}
$$

The coefficient $\mathrm{C}$ can be obtained from the equation (12) for $\mathrm{Pq}=1$ then

$$
\frac{1}{C}=\int_{-\infty}^{\infty} \mathrm{e}^{\left[-\frac{2 \zeta \omega_{\mathrm{n}}}{\pi S o}\left(\frac{1}{2} \alpha \mathrm{x}^{2}+\frac{1}{4} \beta \mathrm{x}^{4}\right)\right]} \mathrm{dx}
$$


Variance of modal displacement according the following equation :

$$
\begin{aligned}
\sigma_{\mathrm{q}}^{2} & =\int_{-\infty}^{\infty} \mathrm{x}^{2} \mathrm{P}_{\mathrm{q}} \mathrm{dx} \\
& =\mathrm{C} \int_{-\infty}^{\infty} \mathrm{x}^{2} \mathrm{e}^{\left[-\frac{2 \zeta \omega_{\mathrm{n}}}{\pi \mathrm{So}}\left(\frac{1}{2} \alpha \mathrm{x}^{2}+\frac{1}{4} \beta \mathrm{x}^{4}\right)\right]} \mathrm{dx}
\end{aligned}
$$

Response stochastic system can be obtained in the form of a standard deviation of modal displacement

$$
\sigma_{q}=\sqrt{\sigma_{q}^{2}}
$$

\section{MONTE CARLO SIMULATION}

According to the procedure of Monte Carlo simulation, the excitation force $\mathrm{W}(\mathrm{t})$ in equation (10) generated digitally and response system displacement $\mathrm{q}(\mathrm{t})$ calculated in accordance with the procedures of numerical finite difference method. $\mathrm{W}_{\mathrm{k}}$ random variable excitation due to white noise and the variance associated with the intensity of the (Do) and the time interval $\Delta \mathrm{t}$, which is in the form of discrete representation of white noise [8] based on the Figure (2a)

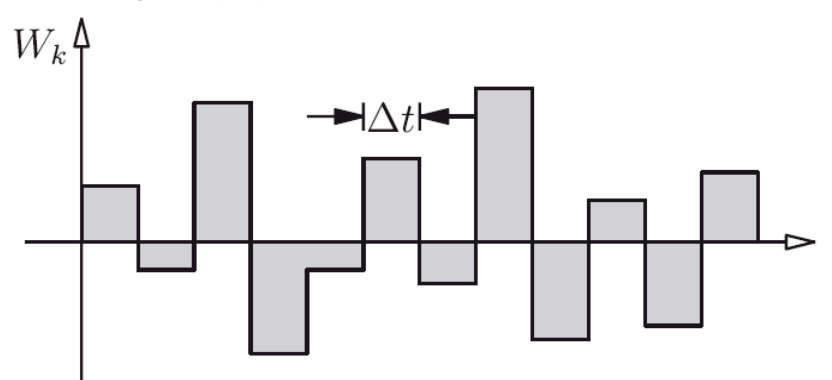

Fig. 3. White Noise Discrete ${ }^{[8]}$

The magnitude of the variance

$$
\sigma_{\mathrm{wk}}^{2}=\frac{\mathrm{D}_{0}}{\Delta \mathrm{t}}=\frac{2 \pi \mathrm{S}_{0}}{\Delta \mathrm{t}}
$$

Variabel $\mathrm{W}_{\mathrm{k}}$

$$
\mathrm{W}_{\mathrm{k}}=\sqrt{\frac{\mathrm{D}_{0}}{\Delta \mathrm{t}}} \mathrm{U}_{\mathrm{k}}=\sqrt{\frac{2 \pi \mathrm{S}_{0}}{\Delta \mathrm{t}}} \mathrm{U}_{\mathrm{k}}
$$

For the Uk is the generation of random numbers, with application software MATLAB.

\section{RESPONSE DETERMINISTIC OF MODAL DISPLACEMENT}

For the case in the form of non-dimensional deterministic according to the equation $(7,8)$, with the value of the damping factor $\xi=0.05 ; \alpha=0.5$; $\beta=0.53 ; \Omega=0.16$.

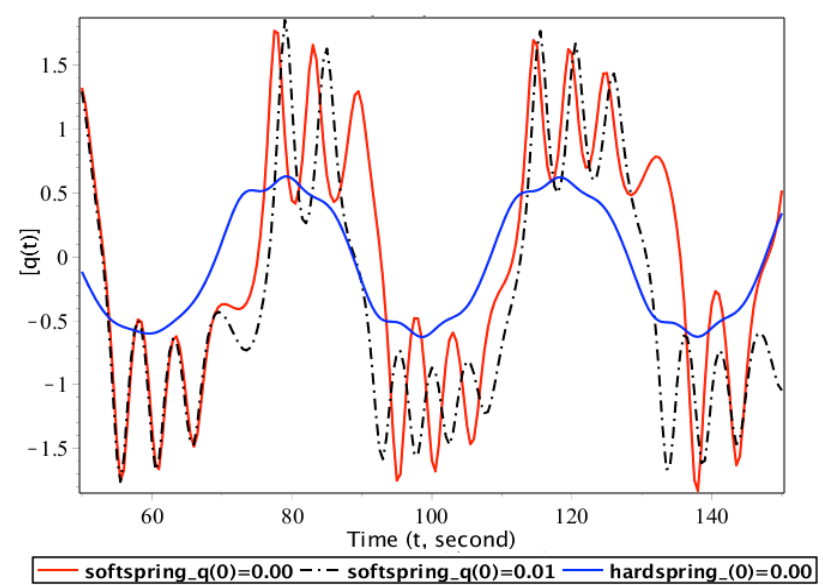

Fig. 4. Time History Modal Displacement

In the nonlinear system, for deterministic response seen with the case of a linear spring $(\beta=0)$, hard spring $(\alpha=0.50)$ and a soft spring $(\alpha=-0.50)$, based on the results of the analysis as shown Figure (4), displacement greater responsiveness on the system soft spring than the hard spring and also obtained in the soft spring, the system shows the response of chaotic, which with small changes in initial conditions $\mathrm{q}(0)=0.00$ becomes $\mathrm{q}(0)=0.01$, the response of modal displacement of the system there will be a large difference with increasing time ( at $t=70$ second begin to change). In the phase plane (Figure 5), for a soft spring system, the trajectory is never repetitive and non-stationary for a long time while in the hard spring system shows the

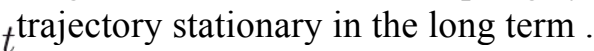

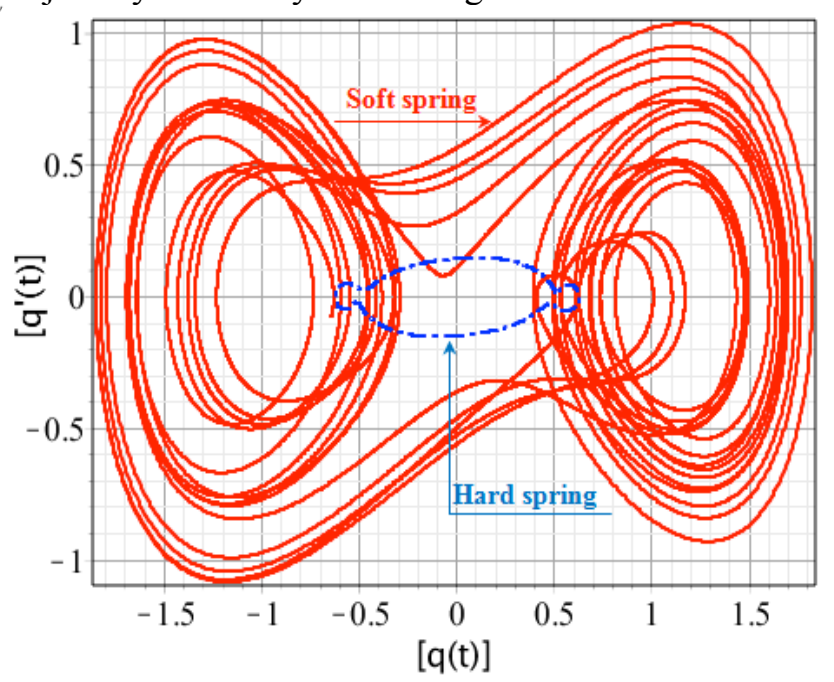

Fig. 5. Phase Plane

Symptoms chaotic on the soft spring system can also be identified by mapping the Poincare $[10,13,16]$, which shows the track with a fractal pattern. 


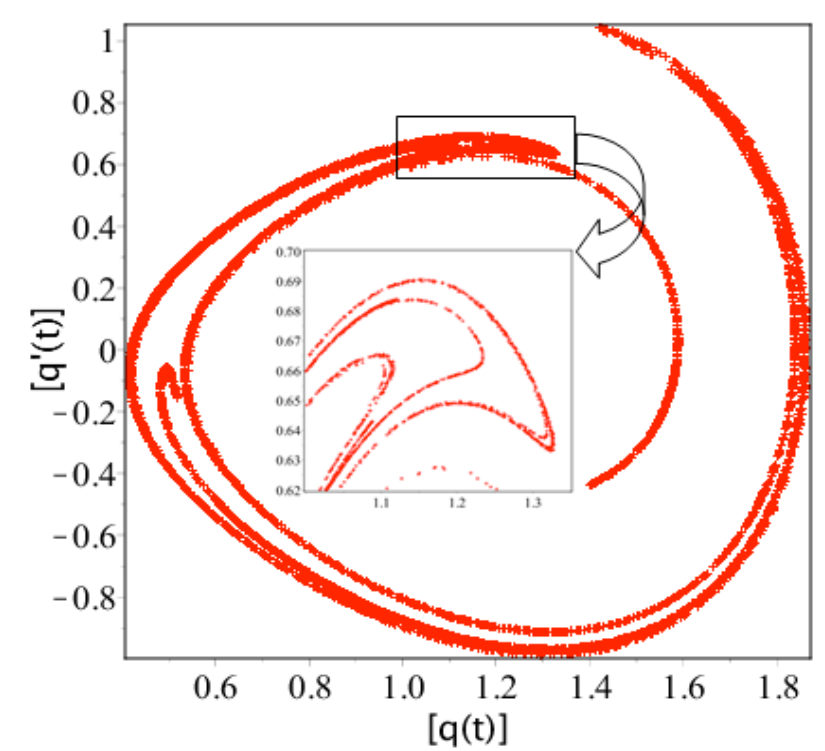

Fig. 6. Poincare Map, soft-spring, $(\alpha=-0.50)$

\section{RESPONSE STOCHASTIC OF MODAL DISPLACEMENT}

For the case of stochastic according to the equation (8) and (10), with the value of the damping factor $\zeta=0.05 ; \beta=0.53$; So spectral density $=1$, variations in the value of $\alpha$ ( hard spring $\alpha=1$ ), soft spring ( $\alpha=-25.0$ ). Based on the equation of the Fokker-Planck-Kolmogorov (FPK) according to equation (11), to the completion of steady state conditions according to equation $(12,13,14)$. According to the equation (12) can be obtained probability density function ( PDF ) as shown figure (8) for linear spring, hard spring and soft spring.The standard deviation of the modal displacement can be obtained by equation (15). Standard deviation value for the linear spring $(\alpha=1, \beta=0.00) \sigma_{q}=5.605$ units, nonlinear hard spring $(\alpha=1, \beta=0.53) \quad \sigma_{q}=2.174$ units, and nonlinear soft spring $(\alpha=-25, \beta=0.53)$ $\sigma_{\mathrm{q}}=6.766$ units (see figure 8)

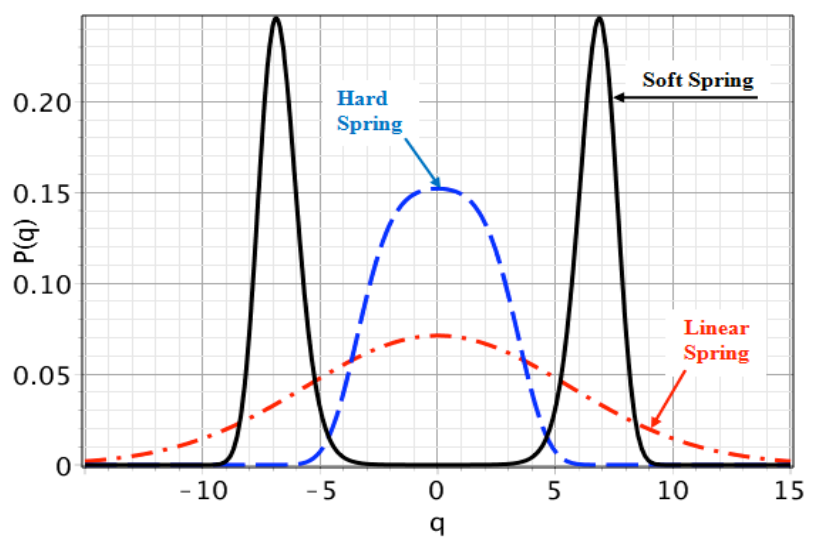

Fig. 7. Probability Density Function (PDF) of Modal Displacement
Based on Monte Carlo simulation according to the equation (7, 17 ) with 1000 simulation (NSIM), and the time interval $(\Delta t) 0.05$ seconds, it takes about 23.119 second computing (cputime). The simulation results at time $\mathrm{t}=100$ second, standard deviation of modal displacement $\sigma_{\mathrm{q}}=6.787$ units. Monte Carlo simulations show an accurate result of the completion of the analytical methods of the FokkerPlanck-Kolmogorov (FPK method) with an error rate $\varepsilon=0.31 \%$.

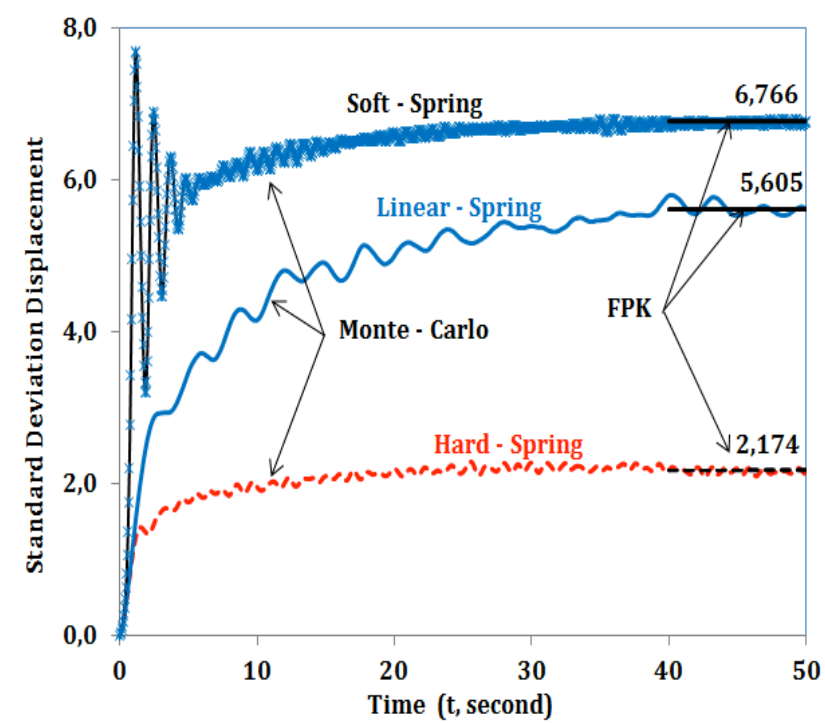

Fig. 8. Standard Deviations of Displacement (MC $=$ Monte Carlo, FPK = Fokker-Planck-Kolmogorov $)$

\section{CONCLUSION}

Displacement response of nonlinear structural system due to a combination of stretching and axial force in deterministically is soft spring with typical symptoms of type chaotic that is very sensitive to the initial conditions of the system. With a small change in the initial conditions, the system response will change with increasing time. Connection with the stochastic response obtained important thing is the amount of displacement standard deviation, where the soft spring which is useful in the design concept plan of the structure.

\section{ACKNOWLEDGMENT}

The author* would like to thank the Ministry of Education and Cultural Affairs, Director General of Higher Education on Postgraduate Scholarship (BPP-DN) for studying at ITB. The authors also thank all the lecturers at ITB FTSL. 


\section{REFERENCES}

(1). Crandall, S.H., and Mark, W.D. Random Vibration in Mechanical Systems. Academic Press, New York. (1973).

(2). Nigam, N.C. Introduction to Random Vibrations. Cambridge, Massachusetts: MIT Press. (1983).

(3). Clough, R.W., Penzien, J. Dinamika Struktur, Jilid 2. Penerbit Erlangga. Jakarta. (1988).

(4). Lin, Y.K., Cai, G.Q. Probabilistic Structural Dynamics, Advanced Theory and Applications. McGraw-Hill. (1995).

(5). Lutes, LD., Sarkani, S. Random Vibrations, Analysis of Structural and Mechanical Systems. Elsevier. (2004).

(6). Benaroya, H., Han, S.M. Probability Models in Engineering and Science. Taylor \& Francis Group. USA. (2005).

(7). Sun, J.Q. Stochastic Dynamics and Control. Elsevier B.V. Amsterdam. (2006).

(8). Bucher, C. Computational Analysis of Randomness in Structural Mechanics. Taylor \& Francis Group, London, UK. (2009).
(9). Wijker, J. Random Vibrations in Spacecraft Structures Design Theory and Applications. Springer Science-Business. (2009).

(10). Argyris, J., Faust, G., Haase, M. An Exploration of Chaos, An Introduction for Natural Scientists and Engineers. NorthHolland. (1994).

(11). Sathyamoorthy, M. Nonlinear Analysis of Structures, USA, CRC Press. (1998).

(11). Meirovitch, L. Fundamentasal of Vibration. McGraw-Hill International Edition. (2001).

(12). Nayfeh, A.H., Pai, P.F. Linear dan Nonlinear Structural Mechanics. John Wiley \& Sons. USA. (2004).

(13). Soong, T.T. Random Differential Equations in Science and Engineering. Academic Press, New York. (1973).

(14) Risken H. The Fokker-Planck equation, Methods of Solution and Applications. Second Edition. Springer-Verlag Berlin Heidelberg. (1989).

(15) Moon, F.C. Chaotic and Fractal Dynamics, An Introduction for Applied Scientist and Engineers.Wiley-VCH Verlag $\mathrm{GmbH} \&$ Co.KgaA. Weinheim. (2004). 